\title{
NUMERICAL FORMULATION IN FINITE ELEMENTS OF DAMPING IN COMPOSITES MATERIALS USING FIRST-ORDER SHEAR DEFORMATION THEORY*
}

Adriana Amaro Diacenco ${ }^{1}$ Debora Junqueira Fonseca

\section{Resumo}

Neste trabalho, os procedimentos para modelagem de estruturas de compósitos do tipo sanduíche que incorporam materiais viscoelásticos são apresentados. A análise numérica foi desenvolvida utilizando a Teoria de Deformação Cisalhante de Primeira Ordem (FSDT), que é implementada em um elemento Serendipity retangular contendo oito nós e cinco graus de liberdade. A incorporação do amortecimento para os modelos de elementos finitos em compósitos de placas laminadas é feita usando a abordagem de módulo complexo e a resolução numérica das equações resultantes do movimento são aspectos particularmente relevantes dos procedimentos de modelagem. Após as discussões de vários aspectos teóricos, as funções de resposta em frequências (FRF's) são calculadas para placas laminadas de compósitos com camada viscoelástica.

Palavras-chave:Estrutura compósita; Material viscoelástico; Modelagem de elementos finitos.

\section{NUMERICAL FORMULATION IN FINITE ELEMENTS OF DAMPING IN COMPOSITES MATERIALS USING FIRST-ORDER SHEAR DEFORMATION THEORY}

\begin{abstract}
In this paper, procedures for the finite element modeling of composite sandwich structures incorporating viscoelastic materials are presented. The numerical analysis was developed using the First-order Shear Deformation Theory (FSDT), which is implemented in a rectangular Serendipity element containing eight nodes and five degrees of freedom per node. The incorporation of the damping into the composite laminated plate finite element models is made by using the complex modulus approach and the numerical resolution of the resulting equations of motion are particularly relevant aspects of the modeling procedures since the viscoelastic stiffness matrix is frequency- and temperature- dependent. After the discussions of various theoretical aspects, the frequency responses functions are calculated for laminated composite plates with viscoelastic layers.
\end{abstract}

Keywords: Composite structures; Viscoelastic materials; Finite element modeling.

1 Licenciada em Física Licenciatura, Mestre em Ciência e Engenharia de Materiais, Professora Pesquisadora, Núcleo de Pesquisa Institucional da FEPI, Centro Universitário de Itajubá - FEPI, Itajubá, Minas Gerais, Brasil.

2 Graduanda em Engenharia Mecânica, Centro Universitário de Itajubá - FEPI, Itajubá, Minas Gerais, Brasil. 


\section{INTRODUCTION}

Composite materials have been increasingly used in various types of engineering systems, especially in aerospace structures, in which structural components must be designed to withstand harsh static and dynamic loading conditions, with typically high reliability levels. The great variety of materials properties and structural configurations makes the numerical modeling of the mechanical behavior of composite structures a complex task. This is a reason for which in the last decades, a great deal of effort has been devoted to the development of finite element models for characterizing the mechanical behavior of such materials, accounting for its typical variations of constructions and various orientations possibilities. Much of the knowledge available to date is compiled in the works by Reddy (1997). In applications in which dynamic loads are involved, the interest in achieving vibration attenuation becomes of capital importance as vibration amplitudes are directly related to fatigue and, as a result, to structural integrity (Chee, 2000; Berthelot, 2006; De Lima et al., 2010). Moreover, the levels of noise and vibration they are subjected passengers of vehiclesis an importante aspectin evaluating the quality of products, and there for impact with respectto their market competitiveness.

Among the various techniques for vibration control which have been devised, the socalled passive techniques have been incorporated in many industrial systems as they present a number of advantages as compared to active strategies such as cost effectiveness, broadband operational effectiveness and inherent stability (Nayak et al. (2005); Rikards et al. 1995; McTavish et al., 1992).

For the purposes of this paper, the First-order Shear Deformation Theory - FSDT is retained and the viscoelastic damping is represented by the complex modulus approach associated with the concept of shift factor and reduced frequency according to the frequency-temperature superposition principle (Lima et al., 2009)

The mathematical modeling has been implemented by using the commercial available software MATLAB®. The numerical results obtained enabled us to evaluate the performance of the viscoelastic materials in reducing the vibration levels on the amplitudes resonance picks and, to illustrate the modeling procedures and incorporation of the viscoelastic damping into finite element models of composite laminated plates systems.

\section{MATERIALS AND METHODS}

\subsection{Background on finite element formulation of composites plates}

The mechanical behavior of the composite structure can be model by using the Firstorder Shear Deformation Theory, in which the displacements at an arbitrary point in such a composite is expressed as follows:

$$
\boldsymbol{U}(x, y, z, t)=\boldsymbol{A}(z) \mathbf{u}(x, y, t)
$$

In Equation (1):

$$
\begin{aligned}
& \boldsymbol{U}(x, y, z, t)=[u(x, y, z, t) v(x, y, z, t) w(x, y, z, t)]^{T} \\
& A(z)=\left[\begin{array}{lllll}
1 & 0 & 0 & z & 0 \\
0 & 1 & 0 & 0 & z \\
0 & 0 & 1 & 0 & 0
\end{array}\right] \\
& \boldsymbol{u}(x, y, t)=\left[u_{0}(x, y, t) v_{0}(x, y, t) w_{0}(x, y, t) \psi_{x}(x, y, t) \psi_{y}(x, y, t)\right]^{T}
\end{aligned}
$$


where $u(x, y, z, t), v(x, y, z, t)$, e $w(x, y, z, t)$ denote the displacements in directions $x, y$ and $z$ respectively. $\left(u_{0}, v_{0}, w_{0}\right)$ and $\left(\psi_{x}, \psi_{y}\right)$ are, respectively, the mid-plane displacements and the cross-section rotations in $x$ and $y$ directions. The usual straindisplacement relations are used and the resulting strains are separated in bending and transverse shear strains, $\boldsymbol{\varepsilon}_{b}$ and $\boldsymbol{\varepsilon}_{s}$, respectively, as follows:

$$
\begin{aligned}
& \boldsymbol{\varepsilon}_{b}(x, y, z, t)=\left[\boldsymbol{D}_{0}+z \boldsymbol{D}_{1}\right] \mathbf{u}(x, y, t)=\boldsymbol{D}_{\boldsymbol{b}}(z) \mathbf{u}(x, y, t) \\
& \boldsymbol{\varepsilon}_{s}(x, y, z, t)=\left[\boldsymbol{D}_{2}\right] \boldsymbol{u}(x, y, t)=\boldsymbol{D}_{s} \boldsymbol{u}(x, y, t)
\end{aligned}
$$

Where: $\quad \boldsymbol{\varepsilon}_{b}(x, y, z, t)=\left[\begin{array}{llll}\varepsilon_{x x} & \varepsilon_{y y} & \varepsilon_{z z} & \gamma_{x y}\end{array}\right]^{T} \quad$ and $\quad \boldsymbol{\varepsilon}_{s}(x, y, z, t)=\left[\gamma_{y z} \gamma_{z x}\right]^{T} . \quad \varepsilon_{x x}=\partial u / \partial x$, $\varepsilon_{y y}=\partial v / \partial y, \quad \varepsilon_{z z}=\partial w / \partial z, \quad \gamma_{x y}=(\partial u / \partial y+\partial v / \partial x), \quad \gamma_{y z}=(\partial v / \partial z+\partial w / \partial y) \quad$ and $\gamma_{z x}=(\partial u / \partial z+\partial w / \partial x)$. Matrices $\boldsymbol{D}_{i}(i=0, \ldots, 6)$ are formed by differential operators appearing in the strain-displacement relations.

Discretization of the displacement variables is made by using appropriate interpolation functions. Hence, for the eight nodes rectangular plate element, the 5 mechanical variables included in vector $u(x, y, t)$ are interpolated from their corresponding 40 nodal values through the following relation:

$$
\boldsymbol{u}(\xi, \eta, t)=\boldsymbol{N}(\xi, \eta) \boldsymbol{u}(t)
$$

Where: $\boldsymbol{u}(t)=\left[\boldsymbol{u}_{1}^{T}(t) \boldsymbol{u}_{2}^{T}(t) \ldots \boldsymbol{u}_{8}^{T}(t)\right]^{T}$ and $\boldsymbol{u}_{i}(t)=\left[\begin{array}{ll}u_{i} v_{i} w_{i} \psi_{x i} \psi_{y i}\end{array}\right]^{T}(i=1$ a 8$)$.

$N(\xi, \eta)$ of dimensions $5 \times 40$, is the matrix formed by the standard serendipity eightnode shape interpolation functions formulated in local coordinates $(\xi, \eta),-1 \leq \xi \leq 1$.

By associating Equations (1-4), the displacement and strain fields are found to be expressed in terms of the nodal values as follows:

$$
\begin{aligned}
& \boldsymbol{U}(x, y, z, t)=\boldsymbol{A}(z) \boldsymbol{N}(\xi, \eta) \boldsymbol{u}(t) \\
& \boldsymbol{\varepsilon}_{b}(x, y, z, t)=\boldsymbol{D}_{b}(z) \boldsymbol{N}(\xi, \eta) \boldsymbol{u}(t)=\boldsymbol{B}_{b}(\xi, \eta, z) \boldsymbol{u}(t) \\
& \boldsymbol{\varepsilon}_{s}(x, y, z, t)=\boldsymbol{D}_{s} \boldsymbol{N}(\xi, \eta) \boldsymbol{u}(t)=\boldsymbol{B}_{s}(\xi, \eta) \boldsymbol{u}(t)
\end{aligned}
$$

Based on the stress-strain relations, the strain and kinetic energies of the composite plate element can be formulated in terms of the natural variables of strain field and the mechanical material properties. After, Lagrange's equations are used, considering the nodal displacements and rotations as generalized coordinates, to obtain the following elementary mass and stiffness matrices, respectively:

$$
\begin{aligned}
& \boldsymbol{M}^{(e)}=\sum_{k=1}^{n} \int_{z=z_{k}}^{z_{k+1}} \int_{\xi=-1}^{\xi=+1} \int_{\eta=-1}^{\eta=+1} \rho_{k} \boldsymbol{N}^{T}(\xi, \eta) \boldsymbol{A}^{T}(z) \boldsymbol{A}(z) \boldsymbol{N}(\xi, \eta) \operatorname{det}(\boldsymbol{J}) d \eta d \xi d z \\
& \boldsymbol{K}_{b}^{(e)}=\sum_{k=1}^{n} \int_{z=z_{k}}^{z_{k+1}} \int_{\xi=-1}^{\xi=+1} \int_{\eta=-1}^{\eta=+1} \boldsymbol{B}_{b}^{T}(\xi, \eta, z) \boldsymbol{C}_{b}^{(k)}\left(\theta_{k}\right) \boldsymbol{B}_{b}(\xi, \eta, z) \operatorname{det}(\boldsymbol{J}) d \eta d \xi d z \\
& \boldsymbol{K}_{s}^{(e)}=\sum_{k=1}^{n} \int_{z=z_{k}}^{z_{k+1}} \int_{\xi=-1}^{\xi=+1} \int_{\eta=-1}^{\eta=-1} \boldsymbol{B}_{s}^{T}(\xi, \eta) \boldsymbol{C}_{s}^{(k)}\left(\theta_{k}\right) \boldsymbol{B}_{s}(\xi, \eta) \operatorname{det}(\boldsymbol{J}) d \eta d \xi
\end{aligned}
$$


In equations (7-9) $\operatorname{det}(\boldsymbol{J})$ indicates the determinant of the Jacobian of the transformation from the in-plane physical variables $(x, y)$ to the natural variables $(\xi, \eta)$, and matrices $\boldsymbol{C}_{b}^{(k)}\left(\theta_{k}\right)$ and $\boldsymbol{C}_{s}^{(k)}\left(\theta_{k}\right)$ represent, respectively, the orthotropic bending and shear elastic matrices of the kth layer, which are constructed according to the Classical Laminate Theory (CLT) as follows:

$$
\begin{aligned}
& \boldsymbol{C}_{b}^{(k)}\left(\theta_{k}\right)=\boldsymbol{T}_{b}\left(\theta_{k}\right) \overline{\boldsymbol{C}}_{b}^{(k)} \boldsymbol{T}_{b}^{T}\left(\theta_{k}\right) \\
& \boldsymbol{C}_{s}^{(k)}\left(\theta_{k}\right)=\boldsymbol{T}_{s}\left(\theta_{k}\right) \overline{\boldsymbol{C}}_{s}^{(k)} \boldsymbol{T}_{s}^{T}\left(\theta_{k}\right)
\end{aligned}
$$

Where $\overline{\boldsymbol{C}}_{b}^{(k)}$ and $\overline{\boldsymbol{C}}_{s}^{(k)}$ are, respectively, the bending and shear elastic property matrices of the kth layer, referred to its principal orthotropic axis, and $\boldsymbol{T}_{b}\left(\theta_{k}\right)$ and $\boldsymbol{T}_{s}\left(\theta_{k}\right)$ are the associated rotation matrices. Due to its nature of orthotropic composite materials, arrays of material properties defined in local coordinates are transformed to the global system for $\theta$ rotation about the $z$ axis, as shown in Equations (10.a 10.b) and this process is built according to the Classical Theory of Laminates (De Lima et al, 2010).

From the elementary matrices computed for each element of the finite element mesh, the global equations of motion are constructed, accounting for the node connectivity, using standard finite element assembling procedures (Huebner et al, 1982). After assembling, the global equations of motion in the time domain can be written as follows:

$$
\boldsymbol{M} \ddot{\boldsymbol{q}}(t)+\boldsymbol{K} \boldsymbol{q}(t)=\boldsymbol{f}(t)
$$

Where $\boldsymbol{M}=\bigcup_{e=1}^{\text {nelem }} \boldsymbol{M}^{(e)}$ and $\boldsymbol{K}=\bigcup_{e=1}^{\text {nelem }} \boldsymbol{K}^{(e)}$ are the global FE mass and stiffness matrices. Symbol $\bigcup$ indicates matrix assembling and $\boldsymbol{q}(t)$ is the vector of global d.o.f's. $\boldsymbol{f}(t)$ is the vector of generalized external loads.

\subsection{Composite sandwich plates with viscoelastic layers}

For a composite sandwich structure configuration corporation viscoelastic layers between laminated composite plates, the viscoelastic material property matrix must be taking into account the frequency and temperature dependence behavior of the viscoelastic material. By considering that the viscoelastic material properties reported herein are assumed isotropic, the Equations (8) and (9) assume the following forms:

$$
\begin{aligned}
& \boldsymbol{K}_{b}^{(v)}(\omega, T)=\sum_{k=1}^{v} \int_{z=z_{k}}^{z_{k+1}} \int_{\xi=-1}^{\xi_{\xi=+1}} \int_{\eta=-1} \boldsymbol{B}_{b}^{T}(\xi, \eta, z) \boldsymbol{C}_{b}^{(k)}(\omega, T) \boldsymbol{B}_{b}(\xi, \eta, z) \operatorname{det}(\boldsymbol{J}) d \eta d \xi d z \\
& \boldsymbol{K}_{s}^{(v)}(\omega, T)=\sum_{k=1}^{v} \int_{z=z_{k}+z_{\xi}}^{z_{k=-1}} \int_{\eta=+1}^{=+1} \boldsymbol{B}_{s}^{T}(\xi, \eta, z) \boldsymbol{C}_{s}^{(k)}(\omega, T) \boldsymbol{B}_{s}(\xi, \eta, z) \operatorname{det}(\boldsymbol{J}) d \eta d \xi d z
\end{aligned}
$$

where the subscript $(v)$ indicates the elementary viscoelastic zones. $\boldsymbol{C}_{b}(\omega, T)$ and $\boldsymbol{C}_{s}(\omega, T)$ are frequency and temperature-dependent viscoelastic material property matrices. 
The inclusion of the frequency and temperature-dependent behavior of the viscoelastic material can be made by using the so-called Elastic-Viscoelastic Correspondence Principle (Christensen et al, 1982). According to which, for a given temperature, matrices $\boldsymbol{K}_{b}^{(v)}$ and $\boldsymbol{K}_{s}^{(v)}$ can be first generated for the plate element assuming that the longitudinal modulus and/or the shear modulus appearing in matrices $\boldsymbol{C}_{b}(\omega, T)$ and $\boldsymbol{C}_{s}(\omega, T)$ (according to the stress-state) are constant. Then, after the FE matrices are constructed, the frequency-temperature dependency of those moduli is introduced according to the complex modulus approach combined with the Frequency-Temperature Superposition Principle - FTSP. By assuming the widely accepted hypothesis of a constant (frequency independent) Poisson ratio for the thermorheologically-simple viscoelastic materials, $E(\omega, T)$ becomes proportional to $G(\omega, T)$ through the relation $G(\omega, T)=E(\omega, T) / 2(1+v)$. Then, one of the two moduli can be factored-out of the viscoelastic stiffness matrices as follows:

$$
\boldsymbol{K}_{v}(\omega, T)=G(\omega, T) \overline{\boldsymbol{K}}_{v}
$$

Based on the formulation presented in the previous sections, and neglecting other forms of damping, the finite element equations of motion in the frequency domain of the composite sandwich plate incorporating viscoelastic materials, can be expressed as follows:

$$
\boldsymbol{K}(\omega, T)=\boldsymbol{K}_{e}+\boldsymbol{K}_{v}(\omega, T)=\boldsymbol{K}_{e}+G(\omega, T) \overline{\boldsymbol{K}}_{v}
$$

The receptacle or FRF matrix is expressed as:

$$
\boldsymbol{H}(\omega, T)=\boldsymbol{c} \mathbf{Z}(\omega, T)^{-1} \boldsymbol{b}
$$

\section{RESULTS AND DISCUSSION}

\subsection{Composite plate with structural damping.}

To illustrate the computation procedure to obtain the FRFs, as the first example, numerical tests were performed using the FE model of a simple supported square $L_{x}=L_{y}=0.16 \mathrm{~m}$, composite plate as shown in Figure 1 (a) and Figure 1 (b) illustrates the model composed by a total number of 64 finite elements and 225 nodes. The following simply supported boundary conditions are applied on the square composite plate $u_{0}=w_{0}=0$ em $y=0$ and $y=a$, and $u_{0}=w_{0}=0$ in $x=0$ e $x=$ b. The composite plate consists of 5 layers of the same thickness $h / 5(h=a / 128 m)$, with the layups $\left(45 \% 0^{\circ} / 45 \% \% 145^{\circ}\right)$.

The real values of the material properties characteristics of each layer are: $\bar{E}_{1}=172,4 G P a, \bar{E}_{2}=\bar{E}_{3}=6,89 G P a, \bar{G}_{12}=\bar{G}_{13}=3,45 G P a, \bar{G}_{23}=1,38 G P a, v_{12}=v_{13}=0,25$, $v_{23}=0,30, \rho=1566 \mathrm{~kg} / \mathrm{m}^{3}$.

The value of the structural damping factor considered herein is $\eta=0.001$, so that $E_{m n}=\bar{E}_{m n}\left(1+i \eta_{m n}\right), \quad E_{m n}=\bar{G}_{m n}\left(1+i \eta_{m n}\right)$, respectively. The computations consist in obtaining the sensitivities of the driving point FRF corresponding to the point $I$, denoted by $\boldsymbol{H}_{l}(\omega, p)$, as shown in Figure 1(b). 


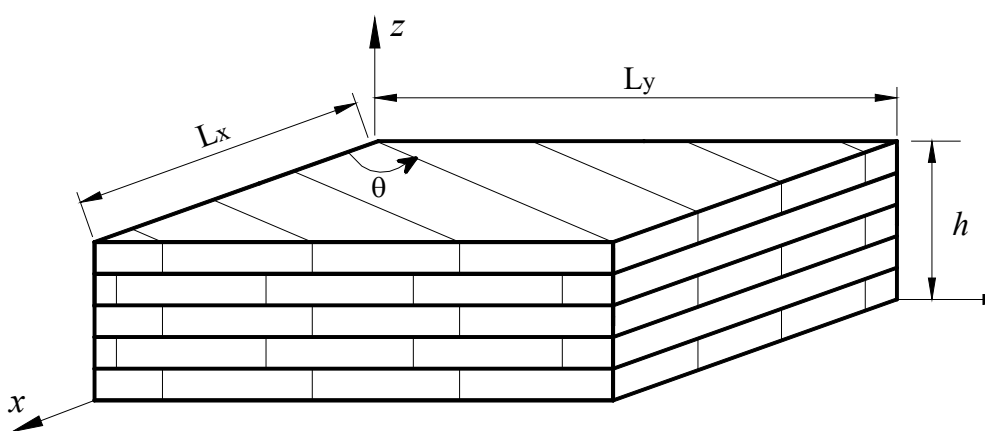

(a)

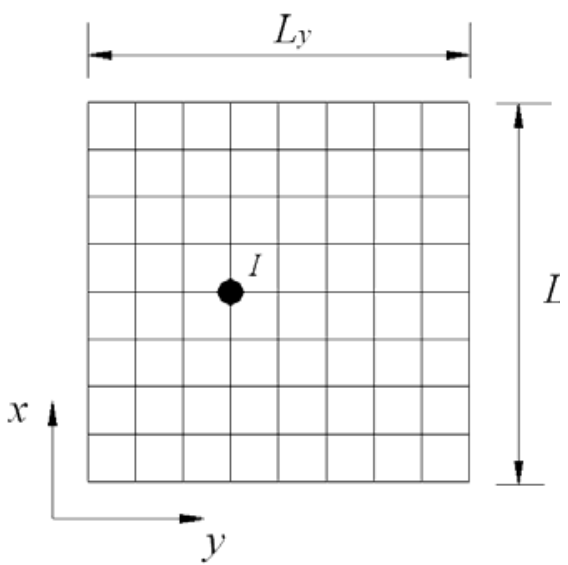

(b)

Fig.1. Illustration of the composite plate geometry (a) and the FE discretization mesh (b).

The Figure 2a shows the FRF amplitudes of the composite material considering the presence of the inherent hysteretic damping obtained through the implementation of the FSDT. Note that the theory used is suitable to describe the amplitudes in FRF. Figure $2 \mathrm{~b}$ shows the FRF amplitudes of the composite material considering the presence of the inherent hysteretic damping. In the same figure are shown the amplitudes of the FRF of the structure without considering the effect of damping. Note that the consideration of the inherent damping of the structure is quite relevant in terms of mitigation of vibration levels corresponding to the resonance peaks.
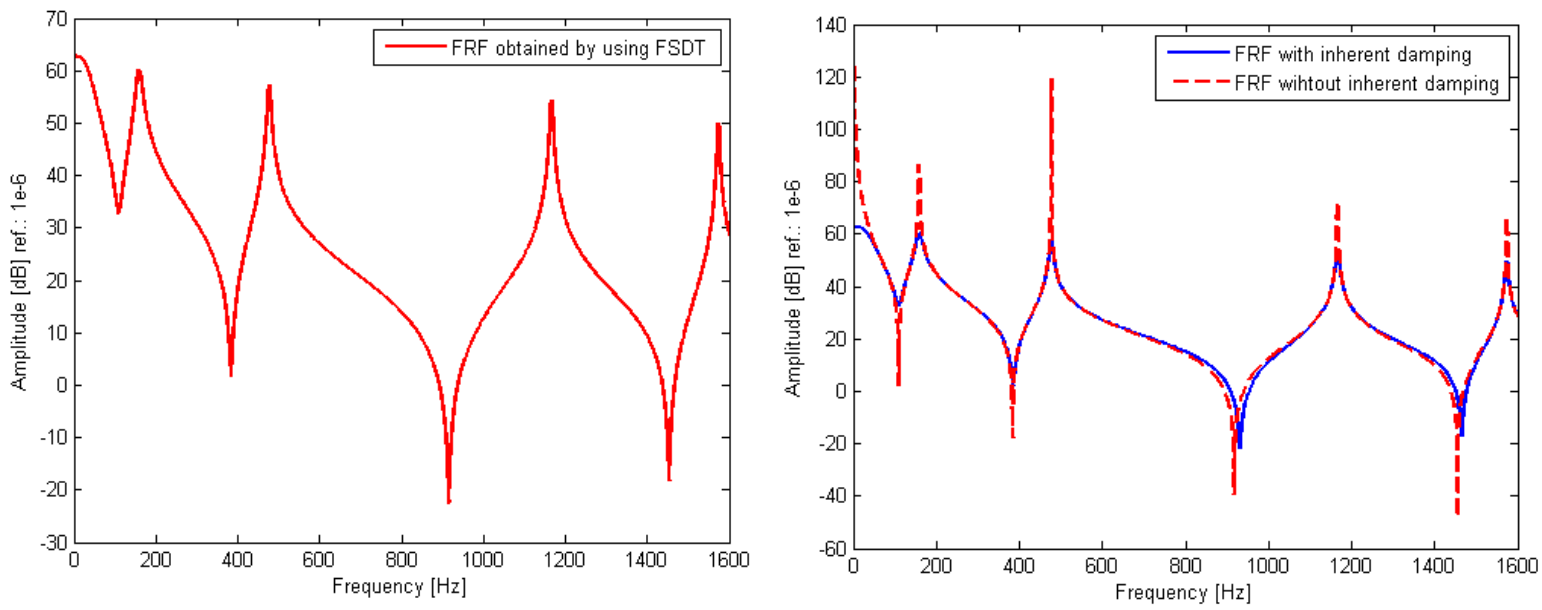

Fig. 2. (a) FRF amplitudes by using FSDT; (b) FRF amplitudes with inherent damping and without inherent damping.

\subsection{Composite sandwich plate with viscoelastic core}

In this application it is considered a sandwich rectangular plate composed by four unidirectional fiber-reinforced composite layers and a polymeric core made of viscoelastic material $3 \mathrm{M}^{\mathrm{TM}} \mathrm{ISD} 112$, and mass density $\rho=950 \mathrm{~kg} / \mathrm{m} 3$.

The finite element discretization, the geometrical characteristics and the boundary conditions of the composite sandwich structure considered here is the same as those of the plate considered in Section 3.1, with the exception that the middle layer consists of the viscoelastic material with thickness $h v=L x / 128$, as illustrated in 
Figure 3. The upper and the bottom fiber-reinforced layers have the same thickness and material properties as those considered in the previous section.

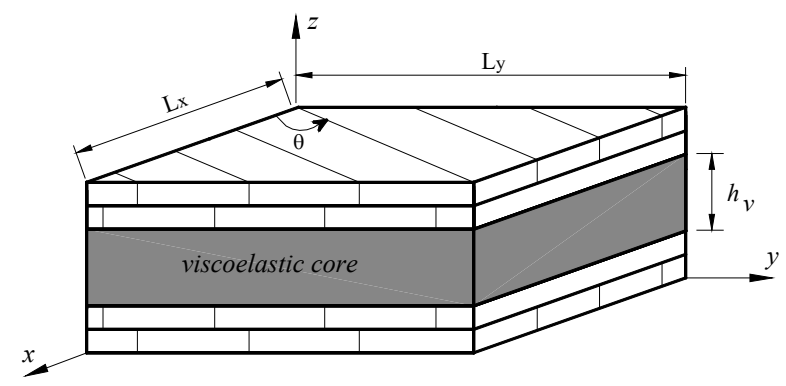

Fig. 3. Illustration of the composite sandwich plate geometry with viscoelastic layer.

In this application was evaluated the influence of temperature on dynamic behavior of the composite laminate containing viscoelastic core, as shown in Figure 4. In addition, it is possible to evaluate the degree of influence of temperature variations within the frequency band of interest.

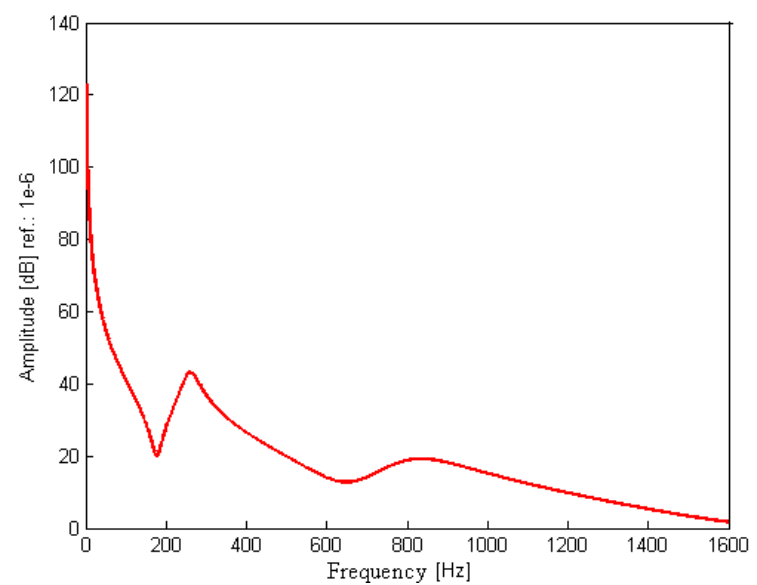

Fig.4. FRF amplitudes with viscoelastic core.

It is worth while mentioning that the results are only reason able described with this theory. The main advantage of using FSDT is that it presents a lower computational cost.

The Figure 5 shows the influence of temperature on dynamic behavior of the composite laminate containing viscoelastic core, In addition, it is possible to evaluate the degree of influence of temperature variations within the frequency band of interest.

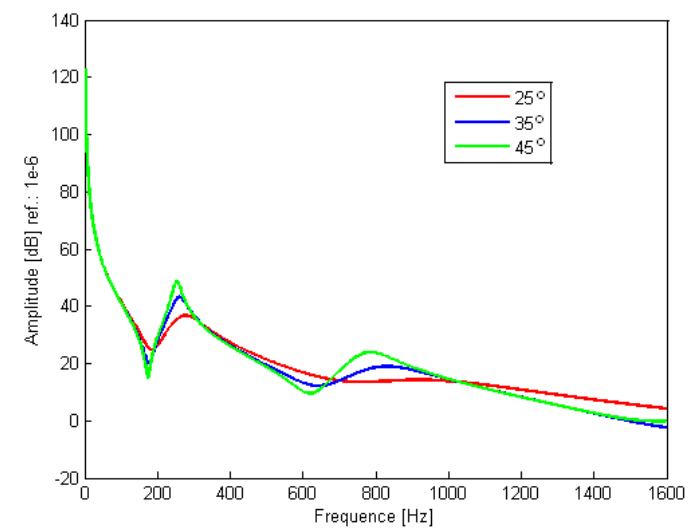

Fig.5. Amplitudes of the FRF's computed considering the variation of the temperature. 


\section{CONCLUSION}

A modeling by finite element models to structural systems containing viscoelastic surface treatments has been suggested, accounting for the dependence of the stiffness matrix with respect to frequency and temperature through the concept of complex modulus.

Applications have been made to rectangular composite sandwich plates though the method can potentially be applied to other types of structural components, which can be very convenient in a number of practical situations.

The use of the complex modulus approach combined with the concepts of shift factor and reduced frequency - justified by the principle of superposition frequencytemperature - has shown to be an adequate strategy to account for the typical dependency of the viscoelastic characteristics with respect to frequency and temperature in the finite element models of complex composite sandwich plates with viscoelastic layers.

\section{Acknowledgements}

The authors are deeply grateful to the following organizations:

Minas Gerais State Agency FAPEMIG for the financial support to their research activities.

Núcleo de Pesquisa Institucional da FEPI.

\section{REFERENCES}

1 Berthelot, J.M. (2006), "Damping analysis of laminated beams and plates using the Ritz method", Compos. Struct, Vol.74 No.2, pp.186-201

2 Chee, C., Tong, L. and Steven, G. (2000), "A mixed model for adaptive composite plates with piezoelectric for anisotropic actuation”, Comput Struct, Vol. 77 No 3, pp. 253-68.

3 Christensen, R.M. (1982), Theory of viscoelasticity: An introduction. Academic Press Inc., New York, USA.

4 De Lima, A.M.G., Faria, A.W. and Rade, D.A. (2010), "Sensitivity Analysis of Frequency Response Functions of Composite Sandwich Plates Containing Viscoelastic Layers", Composite Structures, Vol. 92, pp. 364-76.

5 Huebner, K.H. and Thornton, E.A. (1982), The finite element method for engineers, John Wiley \& Sons, New York, USA.

6 Lima, A.M.G.,Rade, D.A. and Lepore-Neto, F.P. (2009), "An efficient modeling methodology of structural systems containing viscoelastic dampers based on frequency response function substructuring", Mechanical System and Signal Processing, vol. 23 No 4, pp. 1272-81.

7 McTavish, D.J., Hughes P.C., Soucy, Y. and. Graham, W.B. (1992), "Prediction and measurement of modal damping factors for viscoelastic space structures", AIAA Journal, Vol.30 No 5, pp. 1392-99.

8 Nayak, A.K., Moy, S.S.J. and Shenoi, R.A. (2005), "A higher order finite element theory for buckling and vibration analysis of initially stressed composite sandwich plates", Journal of Sound and Vibration, Vol. 286, pp. 763-80.

9 Reddy, J.N.(1997), Mechanics of laminated composite plates: theory and analysis, CRC Press, New York, USA.

10 Rikards, R., Chate, A. and Korjakin, A. (1995), "Vibration and damping analysis of laminated composite plates by the finite element method", Engineering Computations, Vol. 12, pp. 61-74 